\title{
Analysis of contact stress of Hypoid Gear of micro- car rear axle
}

\author{
Jinli $\mathrm{Xu}^{1, a}$, Shangguo Wan ${ }^{1, b}$ and Bing $\mathrm{Xia}^{1, \mathrm{c}}$ \\ ${ }^{1}$ Department of Electrical and Mechanical EngineeringWuhan University of Technology \\ Wu Han, China

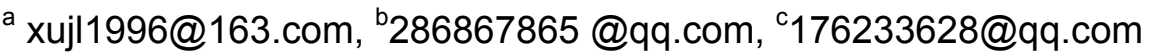

Keywords:hypoid gear; modal analysis; installation location; contact stress

\begin{abstract}
Established a finite element model of hypoid gear of a micro-car rear final drive, analysis of the hypoid gear mode and static contact by means of finite element analysis , obtained the surface of gear contact stress distribution in the different installation position, The results show that the finite element simulation exactly reflects the impact of the installation location of the hypoid gear to contact fatigue strength of gear,providing a theoretical basis for the design and installation of the gear.
\end{abstract}

\section{Introduction}

Automobile rear axle reducer is an important assembly of automotive systems,hypoid gear is the key part that constitutes automobile rear axle reducer. The meshing performance of them impacts directly on the transmission quality and service life of rear axle.Gear drive performance depends not only on tooth machining accuracy, and also closely related to the accuracy of the assembly.By using the finite element method, analysed contact fatigue strength of the hypoid gear, considerated abundantly of the center distance error in the assembly process, which affects the contact stress on the gear, finding out the variation of the gear,to make the design tend to be more reasonable,to ensure that the gear strength to meet the overall design requirements.

\section{Establish the analysis model of hypoid gear .}

Establish the three-dimensional model of hypoid gear. Example, established three-dimensional solid model of hypoid gear in UG which is the modal of of a car provided by the manufacturer. The number of driving gear teeth is eight, The number of driven gear teeth is forty-one. According to cutting machining principle of gear[1], establish the three-dimensional model of the driving and driven gear. After completion of the modeling, to conduct the virtual assembly of driving and driven gears. The assembly process: first, import the driven wheel, then in accordance with the theory of assembly size $X=86 \mathrm{~mm}, Y=52.5 \mathrm{mmZ}=-30 \mathrm{~mm}(\mathrm{Z}=-30 \mathrm{~mm}$ is bias of driving gaear $)$, installed the driving gear . Driving gear rotates around its own axis, until the passive gear do not highlight. After the completion of the model is shown in Figl.

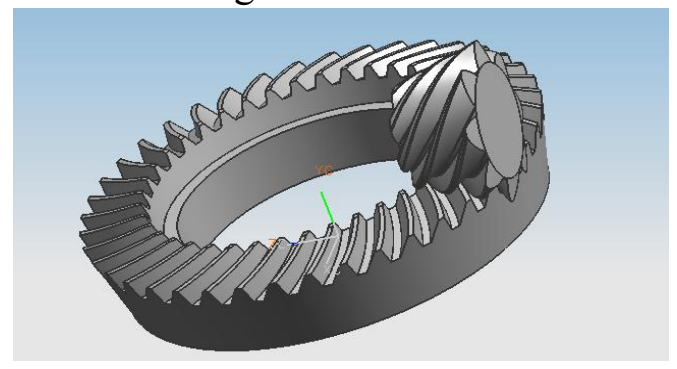

Fig 1 hypoid gear assembly model

Hypoid modal analysis and testing. The model is imported into ansys, selecting the Solid186 (20 nodes) with the node solid elements. Hypoid gear used material for alloy steel (20GrMnTi), density of $7800 \mathrm{~kg} / \mathrm{m} 3$, Young's modulus Ex is 2.06E11, Poisson's ratio of 0.3 . Using smart free meshing gears. And then impose constraints and solved . at last ,to expanse the modal, the results can be observed and analyzed in the universal post processor.The frequency of 
gear vibration usually shows the low and high frequency parts, low frequency general is vibration, high frequency for noise. Therefore, this article focuses on the low-frequency part of the gear, the first six of the driving and drived gears vibration frequency, is shown in Table 1, Table 2:

\begin{tabular}{|l|c|}
\hline level & frequency \\
\hline 1 & 2896.2 \\
\hline 2 & 3205.7 \\
\hline 3 & 5291.2 \\
\hline 4 & 5309.3 \\
\hline 5 & 6408.2 \\
\hline 6 & 6788.0 \\
\hline
\end{tabular}

Table 1 six order natural frequency of driving gear

\begin{tabular}{|c|c|}
\hline level & frequency \\
\hline 1 & 3673.4 \\
\hline 2 & 4108.7 \\
\hline 3 & 4207.5 \\
\hline 4 & 4700.4 \\
\hline 5 & 5102.1 \\
\hline 6 & 5281.3 \\
\hline
\end{tabular}

Table 2 six order natural frequency of Passive wheel

The first order frequency obtained by using finite element analysis is the gear natural frequency, natural frequency of the driving gear and the drived gear were: $2896.2 \mathrm{~Hz}, 3673.4 \mathrm{~Hz}$.

In order to verify the correctness of finite element model,conducting the measurement of gear's natural frequency actually. Through the way of exciting gear,using acceleration pickup collecting vibration signals,continuing increasing frequency of excitation. When the amplitude of gear becomes the biggest during measurement(Resonance), the corresponding frequency is fixed -frequency of gear. For the cause of getting data accurately,conducting the measurement of munificent gears in same model to get fixed-frequency of driving gears and driven gears. The analysis is shown in Table 3 and Table4(confined of space,only lists five pairs of gears), the wave shapes measured in fact are shown in Fig.2 and Fig.3.

\begin{tabular}{|c|c|c|c|c|c|}
\hline Driving Gear Number & 1 & 2 & 3 & 4 & 5 \\
\hline $\begin{array}{c}\text { Vibration Frequency Of } \\
\text { Gear In Axis f (Hz) }\end{array}$ & 2944.34 & 3510.74 & 3096.68 & 3471.68 & 2983.40 \\
\hline
\end{tabular}

Table3.The experimental data of driving gears'fixed-frequency

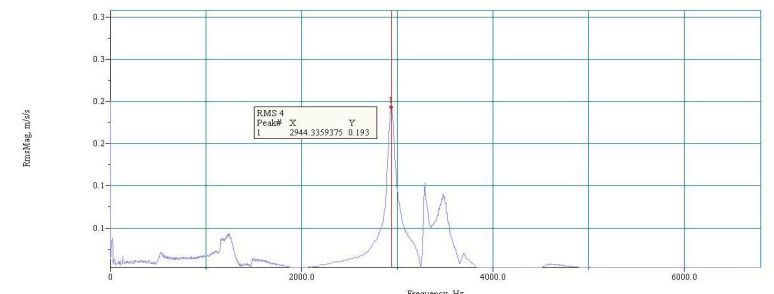

Fig.2.The fixed-frequency of driving gear number 1 .

\begin{tabular}{|l|l|l|l|l|l|}
\hline Driven Gear Number & 1 & 2 & 3 & 4 & 5 \\
\hline $\begin{array}{l}\text { Vibration Frequency } \\
\text { Of Gear In Axis f (Hz) }\end{array}$ & 3505.86 & 3061.52 & 3466.80 & 3481.45 & 3164.06 \\
\hline
\end{tabular}

Table4.The experimental data of driven gears'fixed-frequency

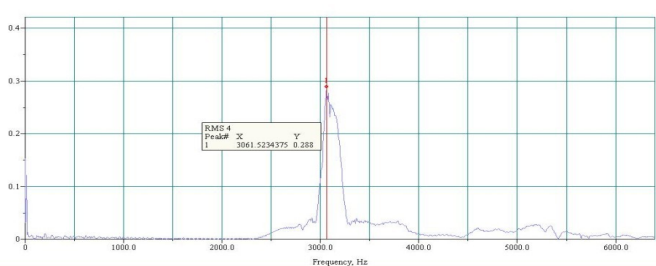

Fig.3.The fixed-frequency of driven gear number 2.

Consideration of different errors in measurement of gear,equally accurate measurement in same group,adopting arithmetic average as an appropriate figure or most reliable figure.

So fixed-frequency of driving gear measured in fact is as followis: 


$$
\bar{x}_{1}=\frac{2944.34+3510.74+3096.68+3471.68+2983.40}{5}=3201.39 \mathrm{~Hz}
$$

Fixed-frequency of driven gear is as follows:

$$
\bar{x}_{2}=\frac{3505.86+3061.52+3466.80+3481.45+3164.06}{5}=3335.94 \mathrm{~Hz}
$$

The fixed-frequency error between analytical calculations by finite element method and measure in fact:

Driving gear's error analysis: $d_{1}=\frac{\Delta x}{x_{1}}=\frac{|3201.39-2896.2|}{3201.39}=9.5 \%$
Driven gear's error analysis: $d_{2}=\frac{\Delta x}{x_{2}}=\frac{|3335.94-3673.39|}{3335.94}=9.9 \%$

Comparative analysis with the result, we can see:The error between analytical calculations by finite element method and measure in fact is in 10 percent. The figures between theory and experiment is in substantial agreement.It shows that the Three-dimensional model built has high precision. The theoretical analysis is high reliable.

\section{The Establishment Of The Quasi-Hyperboloid Finite EIment Model}

Hypoid gear model is complex.If analyzing the entire gear,there will has large amount of calculation. When building finite element model,considering the calculation accuracy, the scale of the model and the calculation's economy,simplified Three-dimensional model as shown[2,3].Now, only analysing one pair of gears' contact conditions,installing accord to the actual installation location,adding tangent constraint. When all of that are finished,importing the Three-dimensional model into ANSYS.Simplified model imported is shown in Fig.4.

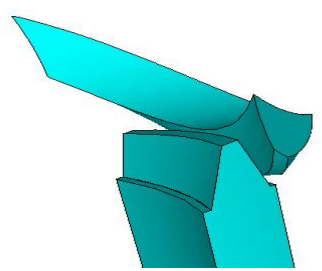

Fig.4.Gear's Simplified Model

Select The Unit And Set The Material Properties. For imported solid model,Selecting SOLID45 solid elements. The SOLID45 solid elements are No node hexahedron elements. There are a total of eight nodes.Freedom of each node has $\mathrm{x}, \mathrm{y}$, and $\mathrm{z}$ direction. The SOLID45 solid elements can reduce the number of nodes, reducing the amount of computation, and ensuring the accuracy.

Meshing. After simplifying the model,the small gear teeth has six surfaces.Meet the requirements of the mapped meshing.Adopting the mapped meshing method.The big gear's model has ten surfaces.More than six sides, so it can't adopt the mapped meshing method.Sweep division method can be used.

Defining Contact Pairs.Choiceing the driving gear as the target surface and driven gear as contact surface.Through contacting with the manager, using contact guidance,selecting the contact unit CONTA174 and the target unit TARGE170 automatically. At the same time,checking the contact direction of the target surface.According to 3-D contact problems, target unit number should make exterior Normal direction of the target surface point to the contact surface.Exterior normal direction is defined by the right hand principle.If the program can not perform the analysis,checking the normal direction[4]. The contact pair is shown in Fig5. 


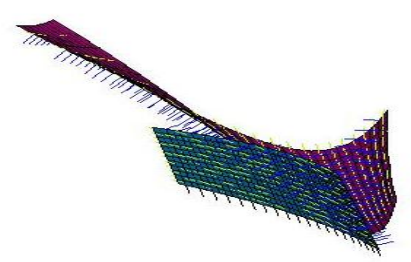

Fig5.Gear's contact pair

The definition of the boundary conditions and loads . After complete the finite element model, then define the boundary conditions, as well as impose loads, and then solve. Imposing circumferential to the driving wheels torque, Under normal circumstances, Exert $100 \mathrm{~N} \cdot \mathrm{m}$ torque to the bottom face of the teeth, Through the underside Imposed the loads on the bottom face of the finite element node. The radial displacement and axial displacement of the inner diameter edge of the driving wheels was fixed. Select the node on the tooth underside, impose constraints. Passive wheel displacement boundary conditions are as follows: The underside of passive wheels is fixed. Limit the three degrees of freedom of moving at the bottom of the gear. Select the tooth underside at first, Then select the node, And impose the constraints on the node. By the same method to complete the set of the passive wheel displacement load, After the completion of the finite element model is shown in Fig 6.

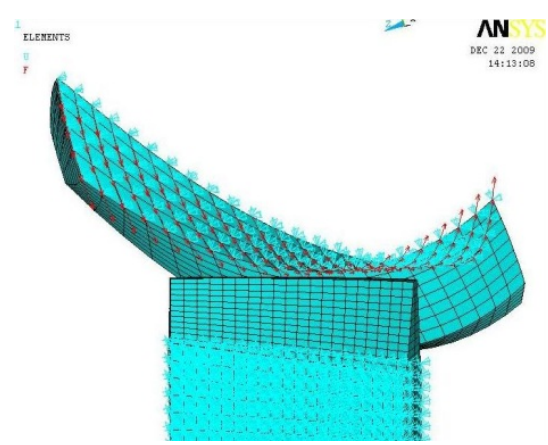

Fig6. The constraint and load on the tooth

\section{The hypoid gear contact stress analysis.}

As the transmission accuracy of the gear depends not only on the machining accuracy of the tooth, also depends on the accuracy of the assembly, Assembly errors are come from the center distance error $[5,6]$. In this paper, We analysis the impact of the installation center distance error to the hypoid gear contact stress, analysis the contact stress in the normal assembly and assembly center distance error.In the assembly process the center distance error limit is $0.3 \mathrm{~mm}$, According to the limit to consider the contact analysis. The specific process is as follows: Assembly the driving wheel along the axial in the theoretical position, Shifted to the right $0.3 \mathrm{~mm}$, and shifted to the left $0.3 \mathrm{~mm}$, is shown in Fig7. Contact analysis the gear respectively in these three positions, Come to the impact of the center distance error of gear to the contact stress.

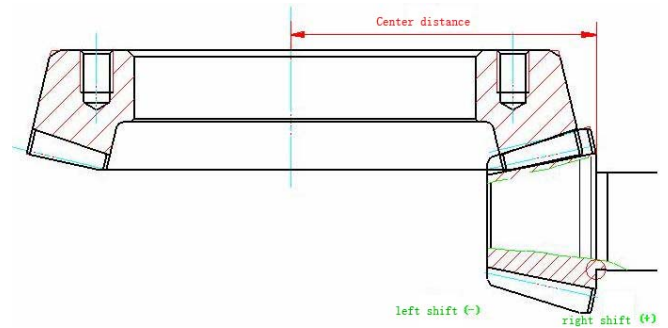

Fig7.The diagram of hypoid gear assembly location

Fig 8, Fig 10, Fig12, respectively show the passive wheel installation position in the theoretical, center distance shifted to the right $0.3 \mathrm{~mm}$, center distance shifted to the left $0.3 \mathrm{~mm}$, the diagram of the tooth surface contact stress. Fig 9, Fig11, Fig13, respectively show the driving wheel installation location in the theoretical,center distance shifted to the right $0.3 \mathrm{~mm}$, center distance shifted to the left $0.3 \mathrm{~mm}$, the diagram of the tooth surface contact stress. 


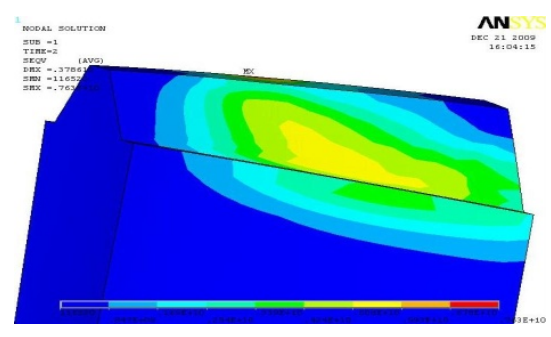

Fig8: The stress cloud of passive wheel theory install location

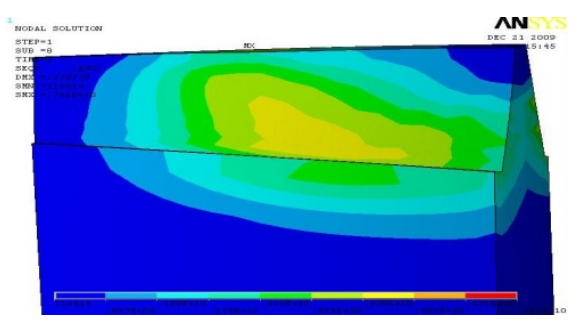

Fig10: The stress cloud of passive wheel shifted to the right $0.3 \mathrm{~mm}$

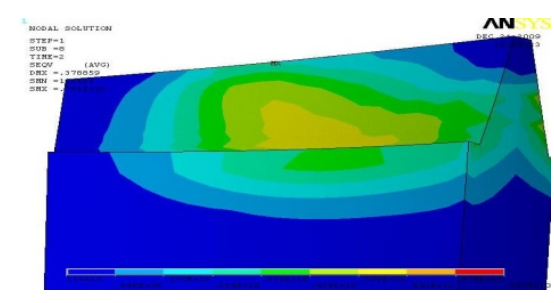

Fig12: The stress cloud of passive wheel shifted to the left $0.3 \mathrm{~mm}$

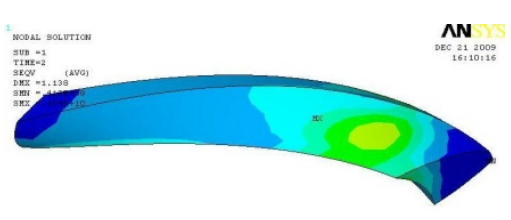

Fig 9: The stress cloud of active wheel theory install location

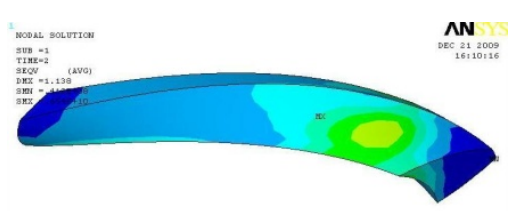

Fig11: The stress cloud of active wheel shifted to the right $0.3 \mathrm{~mm}$

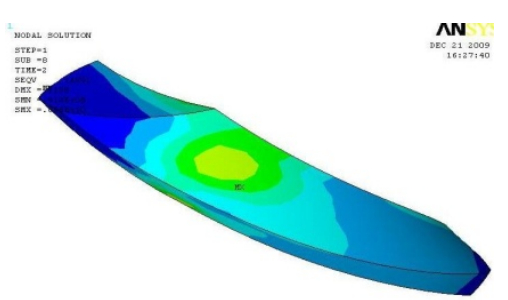

Fig12: The stress cloud of active wheel shifted to the left $0.3 \mathrm{~mm}$

From the above stress cloud, Can clearly see that the contact area was elliptical in shape, the stress of the contact center is the maximum value, decreases gradually to the surrounding, in the gear pair transmission process, tooth constantly under alternating load, the internal stress also is the alternating stress, the gear repeating the process from zero to maximum stress, basically consistent with the actual situation. Respectively statistic the center distance error displacement and equivalent stress of the passive wheel and driving wheel in different limit position. As shown in Table 5,6.

\begin{tabular}{|l|l|l|l|}
\hline Location Category & $\begin{array}{l}\text { Maximum } \\
\text { displacement } \\
(\mathrm{mm})\end{array}$ & $\begin{array}{l}\text { Minimum } \\
\text { equivalent stress } \\
\text { (MPa) }\end{array}$ & $\begin{array}{l}\text { Maximum } \\
\text { equivalent stress } \\
\text { (MPa) }\end{array}$ \\
\hline $\begin{array}{l}\text { Theory installation } \\
\text { location }\end{array}$ & 0.378618 & 0.116520 & 763 \\
\hline $\begin{array}{l}\text { Center distance to } \\
\text { the left offset of } \\
0.3 \mathrm{~mm} \text { distance to }\end{array}$ & 0.378859 & 0.116626 & 769 \\
\hline $\begin{array}{l}\text { Center dight offset of } \\
\text { the righe } \\
0.3 \mathrm{~mm}\end{array}$ & 0.116581 & 763 \\
\hline
\end{tabular}

Table 5 Passive wheels in different locations of displacement and stress table

\begin{tabular}{|l|l|l|l|}
\hline Location & $\begin{array}{l}\text { Maximum } \\
\text { displacement } \\
(\mathrm{mm})\end{array}$ & $\begin{array}{l}\text { Minimum } \\
\text { equivalent stress } \\
(\mathrm{MPa})\end{array}$ & $\begin{array}{l}\text { Maximum } \\
\text { equivalent stress } \\
(\mathrm{MPa})\end{array}$ \\
\hline Theory installation & 0.138 & 0.107419 & 654 \\
\hline
\end{tabular}




\begin{tabular}{|l|l|l|l|}
\hline location & & & \\
\hline $\begin{array}{l}\text { Center distance to } \\
\text { the left offset of }\end{array}$ & 0.142 & 0.108215 & 663 \\
$0.3 \mathrm{~mm}$ distance to & 0.138 & 0.107826 & 654 \\
\hline $\begin{array}{l}\text { Center of } \\
\text { the right offset of } \\
0.3 \mathrm{~mm}\end{array}$ & & \\
\hline
\end{tabular}

Table 6 Driving wheel in different locations of displacement and stress table

From table 5, table 6 can be seen that the driving wheel's displacement and equivalent stress is minimal when it is in the theory of the installation location. When the ferry moves to the left (center distance decreases), the displacement and equivalent contact stress has increased, in line with the actual situation. When ferry moves to the right (center distance increases), the displacement and equivalent contact stress remained unchanged, but increased engagement clearance will increase the engagement shock and dynamic load, which can make the gear transmission unstable, resulting in larger vibration and noise. Therefore, during the installation process of the hypoid gear, the center distance error must be kept within reasonable limits.

\section{Conclusion}

Through the alignment of hypoid gears in different installation location for static contact analysis, we obtained contact force variation in the different installation location, as well as the impact of different installation position of the gear contact fatigue strength. The analysis showed that the stress concentration in loading is maximum, the closer the part away from the contact area, the greater the stress, the tooth cross-section the central stress is minimum. Seen that the gear pair in the transmission process, the tooth constantly bears alternating load, the internal stress is the alternating stress, and the gear is repeating the process from zero to maximum stress. Tooth surface stress suffers the most, and is prone to contact fatigue, resulting in loss, pitting and other defects.

\section{References}

[1] Wang.Xiu-Shan,Yang.Jian-Guo,Wu.Hao. Building research on virtual prototype of gear speed reducer based on Pro/E, ADAMS and ANSYS [J].Journal of Shanghai Jiaotong University.2007, 41(1):1-4

[2] Li.San-Qun,Jia.Chang-Zhi,Wu.Cai-Gang,Liu.Hai-Ping. Dynamic simulation study of gear meshing based on virtual prototyping technology[J]. Journal of System Simulation.2007, 19(4):901-904

[3] Peng.Tao,Lim.Telk C. Dynamics of hypoid gears with emphasis on effect of shaft rotation on vibratory response [J]. 2007 Proceedings of the ASME International Design Engineering Technical Conferences and Computers and Information in Engineering Conference.2008,(7):377-383

[4] Li.Sheng-Peng,Fang.Zong-De. Dynamic frequency calculation of the spiral bevel gear under prestress [J]. Journal of Aerospace Power.2006,21(5):949-955

[5] Cao Xuemei,Fang Zongde,Xu Hao,Su Jinzhan. Design of pinion machine tool-settings for spiral bevel gears by controlling contact path and transmission errors [J]. Chinese Journal of Aeronautics.2008,(21):179-186

[6] Xu Jlinli ,Zhang Bingwei Research and Development of Experiment Platform for Micro-vehicle Rear Axle[J].MACHINERY.2008,46(10) 